\section{VII - Conclusão}

Como eu me desincumbi dos objetivos a que me propus no início desse ensaio? Meu primeiro objetivo era o mapear diversas concepções rivais da arché do direito privado. Três concepções rivais foram identificadas nas seções II e III, a saber, as concepções funcionalista, autonômica e aristotélico-tomista. A seguir um aspecto da concepção aristotélicotomista, qual seja, a noção de que certos tipos de considerações, ainda que aparentemente aplicáveis ao caso concreto, são irrelevantes (ou tem reduzida relevência) em se tratando de relações tipicamente privadas. Se isso é correto, a tarefa fundamental de uma teoria do direito privado é identificar que tipos de relação (e.g. relações de liberalidade ou relações comutativas) exigem ou excluem que tipos de consideração do processo decisório (considerações que dizem respeito ao equilíbrio das partes, à maximização de um bem coletivo, etc). Essa tarefa já é parte da agenda dos teóricos do direito privado, como procurei demonstrar em minha breve análise da teoria da causa, elaborado na seção IV. Esse artigo não pretende revolucionar a agenda de preocupações dos teóricos do direito privado. Uma tal revolução é a negação do tipo de desenvolvimento orgânico que caractreriza o direito privado, talvez a forma de razão prática que, na modernidade, mais conserva a estrutura da razão-techné (i.e. a concepção clássica de razão que tentei delinear na quinta seção desse artigo). O que esse artigo pretende é oferecer aos teóricos do direito privado, que já estão engajados desde sempre num determinado projeto de racionalidade ( racionalidade como techné) uma melho compreensão sobre o processo em que estão envolvidos. Não um novo norte para a pesquisa, mas uma visão mais precisa do norte da pesquisa e do caminho afrente. Nessa visão mais precisa, os modismos revolucionários (como o funcionalismo) e os momentos reacionários (como as tentativas de retornar ao período do absolutismo da concepção autonômica) são vistas como investigações de aspectos parciais de uma teoria mais abrangente do direito privado, uma teoria que as articule como causae que governam aspectos diferentes da vida privada e que em seu conjunto constituem o estatuto do homem privado.

Todavia, ainda que eu tivesse me desincumbido bem das tarefas a que me propus, o leitor ainda tem ao menos uma razão para frustração. Ao início do artigo eu afirmava que eu pretendia contribuir para a determinação da arché do direito privado e oque resultou da investigação foi a existência de diversas archai para diferentes aspectos do direito privado. A questão sobre se existe ou não uma arché unificadora para todo o direito privado não foi resolvida pelo argumento desse artigo. Esse um problema complexo cuja resolução, eu creio demandaria uma forma de abordagem diferente daquela que foi adotada no presente artigo.

\title{
Lei Complementar em Matéria Tributária - A Possibilidade de Revogação por Lei Ordinária ${ }^{1}$
}

\author{
Cristiane Lederzolli Rentzsch \\ Mestranda em Direitos Especiais UFRGS
}

\section{Introdução}

Este trabalho tem por objetivo geral analisar a lei complementar no âmbito tributário, abordando as questões da existência de hierarquia entre as diversas espécies normativas elencadas no art. 59 da Constituição Federal e da reserva da lei complementar.

Especificamente, visa tratar da possibilidade de revogação de lei complementar anterior por lei ordinária posterior, quando a primeira versar sobre matéria diversa daquelas que a Constituição lhe reservou.

Por fim, objetiva analisar o caso concreto da revogação pela Lei $\mathrm{n}^{\circ} 9.430$, de 27 de dezembro de 1996, da isenção da COFINS para sociedades civis, a qual havia sido concedida pela Le Complementar $\mathrm{n}^{\circ} 70$, de 30 de dezembro de 1991.

O tema apresenta-se de extrema importância.

Por insurgir-se no âmbito do Direito Tributário, já é potencialmente gerador de posições controversas, pelo conflito permanente entre o poder arrecadatório fiscal do Estado e os direitos dos contribuintes.
A discussão teórica acerca da existência ou inexistência de hierarquia entre as diversas espécies normativas, bem como da reserva da lei complementar e da possibilidade desta vir a ser revogada por eventual lei ordinária, adquire importância prática na medida em que afeta diretamente a solução de casos concretos.

Portanto, tais questões não se tratam de mero preciosismo acadêmico: refletem-se na prática do universo jurídico a medida em que interfere em situações concretas, beneficiando por vezes o Fisco, e por vezes o contribuinte.

\section{I - LEI COMPLEMENTAR EM MATÉRIA TRIBUTÁRIA}

\section{A) LEI COMPLEMENTAR}

Em sentido amplo, lei complementar é aquela que complementa a Constituição. Segundo o entendimento de Geraldo Ataliba ${ }^{2}$, no sentido doutrinário, o qual se contrapõe ao sentido jurídico-positivo, lei complementar é aquela que completa as disposições constitucionais não auto-executáveis. 
Já, em sentido estrito, adotado pala Constituição de 1988, a expressão lei complementar é utilizada para designar leis previstas para disciplinar matérias especificadas na Constituição, que reclamam quorum especial para sua aprovação.

Portanto, sob o ponto de vista material, a lei complementar apresenta funções específicas, as quais são expressa e exaustivamente previstas pela própria Carta Magna.

Sob o ponto de vista formal, em razão da relevância da matéria, o art. 69 da Constituição Federal exige para sua aprovação quorum qualificado. Assim, determina que as leis complementares apenas serão aprovadas por maioria absoluta, ou seja, pela votação de metade mais um dos membros da Câmara dos Deputados e do Senado Federal.

No âmbito tributário, a Constituição Federal prevê duas espécies de função para a lei complementar, a saber a função precípua de complementar as disposições constitucionais e a função excepcional de criar tributos.

Na vigência da Constituição de 1988, a função precípua é tríplice, uma vez que abrange as três atribuiç̃es previstas nos incisos do art. 146.

Assim, são funções da lei complementar dispor sobre conflitos de competência, em matéria tributária, entre a União, os Estados, o Distrito Federal e os Municípios; regular as limitações constitucionais ao poder de tributar; e estabelecer normas gerais de direito tributário.

Haja vista que a disciplina geral do sistema tributário encontra-se na Constituição, compete à lei complementar detalhá-lo, obedecendo seus

limites. A lei complementar deve apenas explicitar o que está implícito na Constituição, conforme lecionou Pontes de Miranda ainda na vigência da Constituição de 1967:

“(...) Uma vez que a lei complementarnão emenda, apenas complementa, de modo nenhum pode alterar a Constituição e há de ter o conteúdo que a própria Constituição lhe prevê. $(\ldots)^{\prime \prime 3}$

A Constituição traçou o perfil do sistema tributário nacional, identificando cada espécie tributária, bem como impondo os limites ao poder de tributar. Por sua vez, à lei complementar compete estabelecer as regras gerais destes tributos, com o intuito de padronizar o regramento básico da obrigação tributária, conferindo uniformidade ao sistema tributário nacional.

Segundo Sacha Calmon Navarro Coelho ${ }^{4}$ "a vantagem está na unificação do sistema tributário nacional, epifenômeno da centralização legislativa."

Cabe ressaltar que a edição de normas gerais por meio de lei complementar não suprime nem reduz ou substitui o exercício da competência legislativa tributária por parte de cada pessoa política, as quais regulam os tributos de sua competência por meio de lei própria.

Conforme Roque Carrazas, "a le complementar prevista no art. 146 não pode, de nenhum modo, alterar as faculdades privativas que a União, os Estados, os Municípios e o Distrito Federal têm para tributar".

Ainda encontra-se a exigência de le complementar com esta mesma função em outros dispositivos constitucionais esparsos ${ }^{6}$

${ }^{2}$ ATALIBA, Geraldo. Lei Complementar na Constituiçâao, p. 30.

${ }^{3}$ MIRANDA, Pontes. Op. cit. tomo III. p. 150.

${ }^{4}$ COÊLHO, S. C. N. Op. cit. p. 114.

${ }^{5}$ CARRAZA, R. A. op. cit. p. 477

${ }^{6}$ Exemplificativamente: arts. 153 , VII; $155, \S 1^{\circ}$, III; $155, \S 2^{\circ}$, X, "a" e XII; 156, III e $\S 3^{\circ} ; 195, \S 11$.

Revista da Faculdade de Direito da UFRGS, v. 21, Março/2002
Por fim, além de sua função de complementar disposições constitucionais, esta espécie normativa é exigida, excepcionalmente, para a criação de certos tributos. Nesta hipótese a lei terá apenas o nome de complementar, porém, não estará exercendo esta função.

\section{B) LEI NACIONAL}

A República Federativa do Brasil é uma federação, composta pela União, pelos Estados, pelo Distrito Federal e pelos Municípios, todos com autonomia, igualdade de status e competência constitucionalmente delimitada conforme dispõe os arts. $1^{\circ}$ e $18 \mathrm{da}$ Constituição Federal.

Em decorrência, há no sistema jurídico brasileiro a coexistência de ordens jurídicas parciais, quais sejam, as ordens jurídicas federal, estadual e municipal, com a ordem jurídica total ou nacional.

Portanto, há em situação de paridade hierárquica leis federais, estaduais e municipais, dirigidas às pessoas na qualidade de administrados da União, dos Estados e dos Municípios e emanadas do Poder Legislativo dessas entidades políticas, e, concomitantemente, há leis nacionais, ou seja, leis brasileiras, gerais, dirigidas ao povo brasileiro indistintamente.

A lei complementar é lei nacional, posto que subordina as ordens jurídicas parciais, enquanto a lei ordinária é lei federal, já que trata apenas de interesses ordinários da União Federal.

Cabe ressaltar que José Souto Maior Borges $^{7}$ assume posicionamento totalmente diverso, entendendo que tanto a lei complementar, como a lei ordinária da União

${ }^{7}$ BORGES, J. S. M. Lei Complementar Tributária, p. 71

${ }^{8}$ COÊLHO, Sacha Calmon Navarro. Op. cit.p. 98.

Revista da Faculdade de Direito da UFRGS, v. 21, Março/2002 podem revestir-se ou não do caráter de leis nacionais.

Entretanto, segundo a doutrina majoritária, como conseqüencia da lei complementar estar, nas palavras de Sacha Calmon $^{8}$, a serviço da Constituição e não da União Federal, é lei nacional de observância obrigatória pelas ordens jurídicas parciais.

II - REVOGAÇÃO DE LEI COMPLEMENTAR POR LEI ORDINÁRIA

\section{A) RESERVA DA LEI COMPLE-} MENTAREHIERARQUIA DASNORMAS

No ordenamento jurídico brasileiro, vigora com toda sua intensidade o princípio da reserva legal, o qual exige que a regulamentação de determinadas matérias seja feita necessariamente por lei formal.

O legislador constituinte brasileiro, em atendimento ao princípio da reserva legal, delegou competência para o Congresso Nacional legislar sobre determinadas matérias exclusivamente por meio de lei complementar.

Conseqüentemente, as matérias de reserva da lei complementar são aquelas predeterminadas pelo legislador constituinte, cuja utilização não é de decisão do Poder Legislativo.

Portanto, em razão da coexistência em nosso ordenamento de ordens jurídicas parciais e total, nas hipótese em que há expressa previsão de lei complementar por parte da Constituição, é vedado a qualquer outra espécie normativa regular a matéria. 
Todavia, no caso de lei complementar tratar de matéria reservada aos Estados Municípios, interferindo nos seus interesses particulares, esta será inconstitucional por invasão de competência.

Em contrapartida, ao regular matéria da União reservada à lei ordinária, ao invés de inconstitucionalidade, incorre em queda de status, pois terá eficácia apenas de lei ordinária federal. Neste caso, é possível lei complementar tratar de matéria que não pertença à sua reserva, em decorrência da identidade do órgão legislativo emitente de ambas as leis.

Ainda, como o quorum de aprovação da pretensa lei complementar é superior ao exigido para a regulamentação da matéria, não há que se falar em irregularidade formal na sua edição. Nesse caso, a lei não poderá ser considerada lei complementar propriamente dita ou lei materialmente complementar. Dever apenas ser considerada lei formalmente complementar, uma vez que a aprovação por quorum qualificado, por si só, não tem o condão de alterar a substância do instrumento.

A recíproca não é verdadeira. Caso determinada lei ordinária vier a tratar de matéria reservada à lei complementar, esta será inconstitucional.

A lei complementar encontra seu fundamento de validade na Constituição, estando a esta subordinada, assim como as demais espécies normativas previstas no art. 59 da Constituição Federal.É a consagração do princípio da supremacia da Constituição.

Segundo respeitável doutrina, inexiste hierarquia entre lei complementar e lei ordinária, já que ambas possuem campos de atuação diversos. Em decorrência, pode ocorrer invasão de competência, não ofensa ao princípio da hierarquia das leis.

Apenas existe hierarquia quando $o$ ato subordinado extrai seu fundamento de validade do ato subordinante, ou, como afirma Souto Maior ${ }^{9}$, quando este regula a forma de criação daquele

Isto não ocorre no caso, uma vez que todas as espécies normativas elencadas no art. 59 têm como fundamento de validade a própria Lei Suprema. A lei ordinária, definitivamente, não busca seu fundamento de validade na lei complementar.

Somente a circunstância de a lei complementar ser mencionada antes da lei ordinária no elenco do art. 59 do Texto Supremo, não significa que haja posicionamento hierárquico. Da mesma forma, a exigência de quorum de aprovação qualificado não traduz a superioridade hierárquica da lei complementar.

Não obstante considerável parcela da doutrina entender que não há hierarquia entre as referidas espécies normativas no ordenamento jurídico brasileiro, há doutrinadores que ainda vislumbram a existência da suposta hierarquia.

Geraldo Ataliba vislumbrava, na vigência da Constituição de 1967, a hierarquia das normas, na qual a lei complementar sucedia mediatamente a norma constitucional e precedia as leis ordinárias e as demais normas, sobrepondo-se a estas, ou seja, sendo formalmente superior às normas infraconstitucionais.

Afirmava que "as leis complementares, no seu campo estão para as leis ordinárias, assim como as leis constitucionais estão para as leis complementares" ${ }^{\circ}$. E argumentava que a necessidade de aprovação por maioria absoluta em cada Casa do Congresso Nacional emprestava a esta norma superioridade sobre as demais.

${ }^{9}$ BORGES, S. M. B. Lei Complementar Tributária, p. 56.

${ }^{10}$ ATALIBA, Geraldo. Op. cit. p. 30.

Revista da Faculdade de Direito da UFRGS, v. 21, Março/2002
Ressalvava, todavia, que, no caso de determinada lei complementar disciplinar matéria que não pertencesse ao seu campo próprio e exclusivo, não gozaria de qualquer superioridade.

A corrente doutrinária que defendia a hierarquia das normas foi perdendo força, tornando-se obsoleta. Inclusive Geraldo Ataliba $^{11}$ veio, posteriormente, por influência de Souto Maior Borges, reconhecer, de forma categórica, a inexistência da qualquer superioridade hierárquica da lei complementar.

Ainda hoje, Paulo de Barros Carvalho entende que Carta Magna prevê a hierarquia formal da lei complementar sobre as demais espécies normativas. Seu entendimento decorre do parágrafo único do art. 59, o qual estabelece que "Lei complementar disporá sobre a elaboração, redação, alteração $e$ consolidação das leis"'I2.

Ademais, alguns autores ressaltam que em certas hipóteses a lei complementar subordina a lei ordinária e em outras tal subordinação inexiste. A lei ordinária estaria subordinada à lei complementar quando esta fundamentasse sua validade. É o que ocorreria quando a lei complementar determinasse ou insinuasse a elaboração de legislação ordinária necessária à aplicação da lei complementar, ou quando traçasse parâmetros para as matérias tratadas pela legislação ordinária. Em contrapartida, não haveria qualquer subordinação quando a lei complementar cumpre sua função constitucional independentemente da promulgação de outras normas.

Celso Ribeiro Bastos ${ }^{13}$ denomina lei complementar exauriente aquela que incide de

${ }^{11}$ RDPúb. 53/54:61

${ }^{12}$ Após a promulgação da Constituição Federal de 1988 foi editada, em 26.02.1998, a Lei Complementar n ${ }^{\circ} 95$ que disciplinou o art. 59, § único.

${ }^{13}$ BASTOS, Celso Ribeiro. Lei Complementar - Teoria e Comentários, p. 88 maneira direta sobre os fatos regulados, não prescindindo de normação complementar. Em contraposição, denomina lei complementar continuável aquela que permite a coexistência de outra espécie normativa, sendo necessária extensão de sua normatividade por intermédio de lei ordinária. Nesse caso, entende que a le ordinária extrai seu fundamento de validade da lei complementar, sendo a esta subordinada.

Portanto, de acordo com a posição doutrinária majoritária, a qual acolhemos, não há propriamente uma hierarquia entre as leis, apenas cada uma tem seu campo de atuação específico, no qual é autônoma e absoluta.

\section{B) POSSIBILIDADE DE REVo-} GAÇÃ O

No caso de lei complementar tratar de matéria não incluída no seu campo específico de incidência, surge a questão acerca da possibilidade de revogação desta por le ordinária.

Os autores que vislumbram a possibilidade de revogação ou alteração de lei complementar por lei ordinária, quando a primeira extravasar seu campo específico de atuação, argumentam que a opção do legislador de tratar em lei complementar matéria destinada à lei ordinária, não faz com que esta matéria perca sua natureza ordinária.

Logicamente, o equivocado desnecessário tratamento de certa matéria em lei complementar não tem o condão de transformá-la em matéria de reserva da le complementar.

O que eleva uma lei à categoria de lei complementar não é o nome ou a invocação 
que faça o legislador, mas a concorrência dos dois requisitos anteriormente analisados, quais sejam, o quorum qualificado e a matéria constitucionalmente exigida.

Geraldo Ataliba compartilhava do mesmo entendimento, apesar de defender a existência de hierarquia entre as diversas espécies normativas. Para ele, a hierarquia existiria apenas quando a lei complementar estivesse tratando de matéria a ela reservada. No entanto, a lei ordinária poderia perfeitamente dispor sobre qualquer matéria não reservada à lei complementar, inclusive derrogando-a neste campo ${ }^{14}$.

Não obstante o exposto, parte minoritária da doutrina ainda entende que, independente da matéria que esteja regulando, a lei complementar é espécie normativa superior à lei ordinária. Em decorrência, mesmo que disponha sobre matéria a ela não reservada pela Constituição, não poderá ser alterada ou revogada por lei ordinária.

Para embasar este entendimento, faz-se necessário aceitar a hierarquia das leis e conseqüente superioridade formal da le complementar sobre a lei ordinária, independente da matéria que esteja sendo versada.

Apesar da posição doutrinária majoritária no sentido da possibilidade de revogação de lei complementar por lei ordinária, quando a primeira versar sobre matéria não compreendida no seu campo restrito de atuação, o Superior Tribunal de Justiça vem firmando jurisprudência no sentido contrário.

O caso concreto, o qual vem sendo reiteradamente julgado por esta Corte, trata da revogação pela Lei n ${ }^{\circ} 9.430$, de 1996, da isenção da Contribuição para o Financiamento da

Seguridade Social - COFINS para as sociedades civis de que trata o art. $1^{\circ}$ do Decreto-Lei ${ }^{\circ}$ 2.397, de 1987. A referida isenção havia sido concedida pela Lei Complementar n 70 , de 1991 , a qual instituiu a contribuição.

Ocorre que isenção tributária não é incluída entre as matérias abrangidas pela reserva da lei complementar, sendo, portanto, matéria residual, e devendo ser tratada em lei ordinária.

O Ministro José Delgado, componente da Primeira Turma do Superior Tribunal de Justiça, ao relatar o Agravo Regimental no Recurso Especial $n^{\circ} 253.984$, originário do Rio Grande do Sul, se manifestou expressamente que “(...) a revogaçãa da isenção pela Lei $n^{\circ}$ 9.430/96 fere, frontalmente, o princípio da hierarquia das leis, visto que tal revogação só poderia ter sido veiculada por outra lei complementar. (...) “15.

A Segunda Turma do Tribunal Superior também acolhe a posição defendida pela Primeira Turma acerca da impossibilidade de revogação de dispositivo de lei complementar por lei ordinária, independentemente da matéria tratada, tornando pacífica a posição de ambas as Turmas de Direito Público desta Corte.

É o que demonstra o seguinte trecho extraído da decisão da Ministra Nancy Andrighi no julgamento do Recurso Especial n ${ }^{\circ} 261.068$, também originário do Rio Grande do Sul:

“(...) É pacífico o entendimento de ambas as Turmas de Direito Público que a revogação da isenção da COFINS, ainda que seja matéria passivel de inserção em lei ordinária (isenção tributária), não pode viger se o diploma criador da isenção é de hierarquia superior. (...)" 16

${ }^{14}$ ATALIBA, Geraldo. Op. cit. p. 36

${ }^{15}$ STJ; AGREsp 253.984/RS; Rel. Min. José Delgado; 1 Turma; j. 03.08.2000;DJ 18.09.2000, p. 105 ${ }^{16}$ STJ; REsp 261.068/RS; Rel. Min. Nancy Andrighi; 2. Turma; DJ 29.08.2000

Revista da Faculdade de Direito da UFRGS, v. 21, Março/2002
No mesmo sentido é o entendimento da Ministra Eliana Calmon, outra componente da Segunda Turma do Superior Tribunal de Justiça, assim externado no julgamento do Recurso Especial $n^{\circ}$ 226.062:

"Tributário - COFINS - Isenção Sociedade livre: $L C{ }^{\circ} .70 / 91$ - Revogação da isenção pela Lei $n^{\circ}$ 9.430, de 27/12/96. 1 . Estabelecida isenção da COFINS em le complementar, não é lícita a supressão do favor fiscal por lei ordinária. (...)" 17

Portanto, não apenas os Ministros integrantes da Primeira Turma do Superior Tribunal de Justiça, como também os integrantes da Segunda Turma desta Corte, acolhem o entendimento contrário ao da doutrina dominante.

Contudo, a posição adotada recentemente pelo Superior Tribunal de Justiça não é acolhida pacificamente pelos tribunais regionais, assim como pelo Supremo Tribunal Federal.

O Tribunal Regional Federal da $4^{\mathrm{a}}$ Região adota entendimento contrário, vislumbrando a possibilidade da referida revogação, conforme entendimento da Juíza aposentada do Tribuna Regional Federal da $4^{\mathrm{a}}$ Região Tânia Escobar, na Apelação Cível n ${ }^{\circ}$ 98.04.01866-7 ${ }^{18}$.

O mesmo entendimento é encontrado entre os Ministros do Supremo Tribunal Federal, no julgamento da Ação Declaratória de Constitucionalidade $n^{\circ} 1-1$, na qual fo declarada a constitucionalidade da COFINS ${ }^{19}$, conforme o voto do Ministro Moreira Alves, verbis:

“(...) A circunstância de ter sido instituída por lei formalmente complementar - a Lei Complementar $n^{\circ}$ 70/91 - não lhe dá,

${ }^{17}$ STJ; REsp 226.062/SC; Rel. Min. Eliana Calmon; 2. Turma; DJ 10.06.2000

${ }^{18}$ TRF 4. Região; AC 98.04.01866-7/RS; Rel. Juíza Tânia Escobar; 2 Turma; j. 25.03.1999; DJ 12.05.99

${ }^{19}$ STF; ADC 1-1/DF; Rel. Min. Moreira Alves; Plenário; DJ 16.06.1995.

Revista da Faculdade de Direito da UFRGS, v. 21, Março/2002

evidentemente, a natureza de contribuição social nova, a que se aplicaria o disposto no $\S$ 4 do art. 195, porquanto essa lei, com relação aos dispositivos concernentes à contribuição social por ela instituída - que são objeto desta ação, é materialmente ordinária, por não tratar, neste particular, de matéria reservada, por texto expresso da Constituição, à lei complementar. (...) A jurisprudência desta Corte, sob o império da Emenda Constitucional $n^{\circ} 1 / 69-e$ a Constituição atual não alterou este sistema - se firmou no sentido de que só se exige lei complementar para as matérias cuja disciplina a Constituição expressamente faz tal exigência, $e$, se porventura a matéria, disciplinada por lei cujo processo legislativo observado tenha sido a lei complementar, não seja daquelas para que a Carta Magna exige essa modalidade legislativa, os dispositivos que tratam dela se têm como dispositivos de lei ordinária. “

Portanto, em oposição ao entendimento externado pelo Superior Tribunal de Justiça, o Supremo Tribunal Federal, acompanhado do Tribunal Regional Federal da $4^{2}$ Região, acolhe o entendimento favorável à possibilidade de revogação.

\section{Conclusão}

Em suma, entendemos que não existe no sistema jurídico brasileiro hierarquia entre as normas legais, uma vez que todas possuem como seu fundamento de validade a Constituição Federal e estão a ela subordinadas diretamente. Existe apenas a reserva da lei complementar, a qual afasta a possibilidade de outros veículos normativos versarem sobre determinadas matérias. 
Data maxima venia discordamos da posição adotada recentemente pelo Superio Tribunal de Justiça, o qual vislumbra a hierarquia entre lei complementar e lei ordinária, bem como a conseqüente impossibilidade de revogação daquela por esta, independente da matéria versada.

Como consequiência, acolhemos posição adotada pela doutrina dominante, assim como pelos Ministros do Supremo Tribunal Federal, no sentido da possibilidade de revogação no caso específica da le complementar extravasar seu campo de atuação.

Naturalmente, a lei complementa representa uma segurança dos contribuintes na relação jurídica tributária contra eventuais excessos dos poderes impositivos.

Contudo, isto não significa que este veículo normativo possa cristalizar o sistema exigindo que matérias não compreendidas na sua reversa de atuação sejam necessariamente tratadas por lei complementar, unicamente em razão de terem ocasionalmente sido objeto deste instrumento.

Devemos respeitar a opção do legislador constituinte quando este escolheu as matérias tributárias que considerou de interesse da nação e, apenas nestes casos, exigir a utilização do instrumento por ele designado.

\section{Bibliografia}

DOUTRINA

ATALIBA, Geraldo. Estudos e Pareceres de Direito Financeiro. São Paulo: Editor Revista dos Tribunais, 1980. V. III.

. Lei Complementar na Constituição São Paulo: Editora Revista dos Tribunais 1971.

AMARO, Luciano. Direito Tributário Brasileiro. $5^{\text {a }}$ ed. São Paulo: Editora Saraiva, 2000.
BALEEIRO, Aliomar. Limitações Constitucionais ao Poder de Tributar. Atualizado por Misabel Abreu Machado Derzi. $7{ }^{\text {a }}$ ed. Rio de Janeiro: Editora Forense, 1998.

BASTOS, Celso Ribeiro. Lei Complementar Teoria e Comentários. $2^{\text {a }}$ ed. São Paulo: Celso Bastos Editor, 1999.

BORGES, José Souto Maior (coord.). Direito Tributário Moderno. São Paulo: José Bushatsky Editor, 1977.

. Lei Complementar Tributária. São Paulo: Revista dos Tribunais, 1975.

CARRAZA, Roque Antonio. Curso de Direito Tributário Constitucional. $10^{\text {a }}$ ed. São Paulo: Malheiros Editores, 1997.

CARVALHO, Maria Augusta Machado de (coord.). Estudos de Direito Tributário em Homenagem à Memória de Gilberto de Ulhôa Canto. Rio de Janeiro: Forense, 1998.

CARVALHO, Paulo de Barros. Curso de Direito Tributário. $6^{\mathbf{a}}$ ed. São Paulo: Saraiva, 1993.

CASSONE, Vittorio. Direito Tributário. $10^{\mathrm{a}} \mathrm{ed}$. São Paulo: Editora Atlas, 1997.

COÊLHO, Sacha Calmon Navarro. Curso de Direito Tributário Brasileiro. $5^{\text {a }} \mathrm{ed}$. Rio de Janeiro: Editora Forense, 2000

ICHIHARA, Yoshiaki. Direito Tributário. $8^{\mathrm{a}} \mathrm{ed}$. São Paulo: Editora Atlas, 1999.

KELSEN, Hans. Teoria Pura do Direito. $6^{\mathrm{a}}$ ed. São Paulo: Martins Fontes, 2000.

MARTINS, Ives Gandra da Silva (coord.). Lei Complementar Tributária. In: Caderno de Pesquisas Tributárias. São Paulo: Resenha Tributária, v. 15, 1990

. A função da LC tributária - legalidade do Decreto $n^{\circ}$ 3.070/99 e da IN-SRF 060/99 - Possibilidade de Adoção de Imposto fixo no direito tributário. Revista Dialética de Direito Tributário. São Paulo, v. 65, p. 146162, fev. 2001.
MIRANDA, Pontes de Comentários à Constituição de 1967. $2^{\text {a }}$ ed. São Paulo : Revista dos Tribunais, 1970. T. II e III

MORAES, Bernardo Ribeiro de. Compêndio de Direito Tributário. $2^{a}$ ed. Rio de Janeiro: Forense, 1994. V. II.

PAULSEN, Leandro. Direito Tributário Constituição e Código Tributário à Luz da Doutrina e da Jurisprudência. $2{ }^{a}$ ed. Porto Alegre: Livraria do Advogado Editora, 2000.

SILVA, José Afonso da. Curso de Direito Constitucional Positivo. $17^{\text {a }}$ ed. São Paulo: Malheiros, 2000.

\section{JURISPRUDÊNCIA}

ANDRIGHI, Nancy. STJ; REsp n 261.068/RS; $2^{\mathrm{a}}$ Turma; DJ de 29.08.2000.

CALMON, Eliana. STJ; REsp n ${ }^{\circ} 226.062 / \mathrm{SC} ; 2^{\mathrm{a}}$ Turma; DJ 10.06.2000

DELGADO, José. STJ; AGREsp n ${ }^{\circ}$ 253.984/RS; $1^{\text {a }}$ Turma; j. 03.08.2000; DJ de 18.09.2000.

ESCOBAR, Tânia. TRF $4^{\circ}$ Região; AC n ${ }^{\circ}$ 98.04.01866-7/RS; $2^{\mathbf{a}}$ Turma; j. 25.03.1999; DJ de 12.05.1999.

MOREIRA, Alves. STF; RE $n^{\circ}$ 146.733/SP; Pleno; RTJ 143:684.

MOREIRA, Alves e SANCHES, Sidney. STF; $\mathrm{ADC} \mathrm{n}^{\circ} 1$ 1-1/DF; Rel. Min. Moreira Alves; Plenário; DJ 16.06.1995. 